\title{
IDENTIFIKASI MORFOLOGI KAWASAN KAMPUNG MELAYU KOTA SEMARANG
}

\author{
Wahjoerini ${ }^{1}$ \\ Rizqy Ridho ${ }^{2}$ \\ Fakultas Teknik, Universitas Semarang ${ }^{1,2}$ \\ Penulis korespondensi email: wahjoerini@usm.ac.id ${ }^{1}$
}

\begin{abstract}
City development increases with the increase in the number of people living in a city. Urban development as a result of development has created metropolitan cities as centers of growth that drive the urbanization process. The spatial component is not only the background of the inhabitants, but also the physical buildings which become assets to maintain the existence of the village. This is supported by the Trancik theory which states that the physical space theory of cities consists of basic images, linkages, places, and these three theories are complementary. In addition to the morphological theory according to Trancik, to determine physical specifications that are supported by morphology theory which contains the architectural form of an area. By developing cities, urban morphology will also change according to city developments. The process of forming urban morphology is the process of forming city life. An ancient village that still has high historical value and has an important meaning, namely Kampung Melayu. The potential for cultural and ethnic images that have more than one ethnicity makes Kampung Melayu a role in ordering morphology in the city of Semarang. The research objective is to identify the morphology of the Kampung Melayu Semarang. The method used is descriptive qualitative analysis with primary data in the form of observation and secondary data in the form of literature review. The resulting output is the morphology of Kampung Melayu seen from the theory of Ground, Linkage and Place drawings as well as road patterns so that later it can be used to determine the Spatial Plan.
\end{abstract}

Keyword: Morphology, City Development, Kampung Melayu

\begin{abstract}
ABSTRAK
Perkembangan kota ditandai dengan bertambahnya jumlah penduduk yang tinggal di suatu kota. Pembangunan perkotaan dari hasil pembangunan selama ini telah menciptakan kota-kota metropolitan sebagai pusat pertumbuhan yang mendorong proses urbanisasi. Komponen ruang bukan hanya hanya latar belakang penduduknya, namun juga bangunan fisik yang menjadi aset untuk mempertahankan eksistensi kampung. Hal ini didukung dengan teori Trancik yang mengatakan bahwa teori ruang fisik kota terdiri dari figure ground, linkage, place dan ketiga teori ini saling melengkapi. Selain teori morfologi menurut Trancik, untuk menentukan identifikasi fisik didukung dengan teori tipomorfologi yang berisi mengenai bentuk arsitektur suatu kawasan.Dengan berkembangnya kota maka morfologi perkotaan juga akanberubah mengikuti perkembangan kota. Proses terbentuknya morfologi kota (urban morphology) merupakan proses terbentuknya kehidupan kota. Potensi citra budaya serta memiliki etnis lebih dari satu menjadikan Kampung Melayu memberikan peran dalam pembentukan morfologi di Kota Semarang. Tujuan dilakukannya penelitian yaitu untuk mengidentifikasi Morfologi kampung Melayu Semarang. Metode penelitian yang digunakan yaitu analisis deskriptif kualitatif dengan pengumpulan data primer berupa observasi lapangan dan data sekunder berupa kajian literatur. Keluaran yang dihasilkan yaitu berupa morfologi Kampung Melayu dilihat dari teori Figure Ground, Linkage dan Place serta pola jalan sehingga nantinya dapat digunakan untuk arahan dalam menentukan Rencana Tata Ruang.

Keyword: Morfologi Kota, Perkembangan, Kampung Melayu
\end{abstract}




\section{PENDAHULUAN}

Perkembangan kota yang dinamis mengakibatkan tuntutan akan ruang meningkat, terutama kebutuhan akan lahan permukiman (Putri et al., 2016). Kota Semarang terletak di pantai pesisir utara Jawa yang memiliki kawasan historis yang menarik. Kawasan tersebut antara lain Kota Lama, Pecinan, Melayu, Kauman, Sampokong, dan kawasan Candi (Alie \& Suwandono, 2013). Selain itu, Kota Semarang terus mengalami perkembangan terutama di kawasan pusat kota sehingga daerah sekitar pusat kota mendapatkan pengaruh dari perkembangan yang terjadi. Kampung kota mempunyai karakteristik yang unik terkait dengan perkembangan morfologi artefak kota yang banyak dipengaruhi oleh sejarah, aktivitas masyarakat dan fungsi kawasan (Susanti \& Ikaputra, 2020). Kampung juga merupakan tempat tinggal dan bersosialisasi terhadap masyarakatnya (Bahar \& Nursanty, 2012). Kampung Melayu adalah sebuah kampung kuno dengan nilai kesejarahan tinggi serta memiliki arti penting dalam pembentukan kota Semarang. Blok-blok permukiman di Kampung Melayu terjadi karena adanya proses pengelompokan sosial, kekerabatan dan identitas etnik penghuninya (Bahar \& Nursanty, 2012). Beragam artefak arsitektur seperti masjid menara layur, klenteng kampung Melayu, rumah Indis, rumah Melayu, rumah Jawa, rumah Banjar serta beberapa artefak penting lainnya seperti pelabuhan lama Semarang dan kanal baru menjadikan Kampung Melayu merupakan kampung yang memiliki karakteristik beragam. Masyarakat yang menghuni kampung Melayu disamping terdiri dari masyarakat asli Semarang, juga terdiri dari etnis lain seperti Arab, Tionghoa, Banjar, Melayu, Jawa, Cirebon. Keragaman etnis ini memberi peran yang signifikan dalam pembentukan struktur dan pola ruang kampung Melayu.

Perkembangan Kota Semarang melatarbelakangi pembahasan mengenai identifikasi Morfologi Kampung Melayu. Morfologi kota dipengaruhi oleh aspek sejarah yang membentuk dan mempengaruhi perkembangan kota (Sitompul \& Roychansyah, 2018). Pembahasan yang dilakukan merupakan hasil analisis morfologi serta sejarah dan kebeadaan berbagai macam etnis yang berpengaruh terhadap bentuk morfologi di kawasan tersebut. Dari pernyataan diatas, maka muncul pertanyaan penelitian yaitu "Seperti apa Morfologi Kampung Melayu Kota Semarang ?" 


\section{METODOLOGI}

Pendekatan penelitian yang digunakan dalam penelitian ini yaitu jenis pendekatan kualitatif. Tahap awal yang dilakukan untuk mencapai tujuan dalam penelitian ini adalah menelaah teori-teori maupun konsep melalui beberapa literatur dan jurnal yang relevan. Kemudian dilanjutkan dengan survei lapangan untuk mengkaji fenomena dilapangan. Hasil survei tersebut kemudian dianalisis agar dapat menghasilkan temuan studi yang sesuai dengan tujuan penelitian. Untuk tahapan analisis yang pertama yaitu mengetahui sejarah Kampung Melayu, Analisis Figrue Ground, Analisis Linkage, Analisis Place, serta Pola Jalan. Untuk lebih jelasnya, dapat dilihat pada diagram alir dibawah ini :

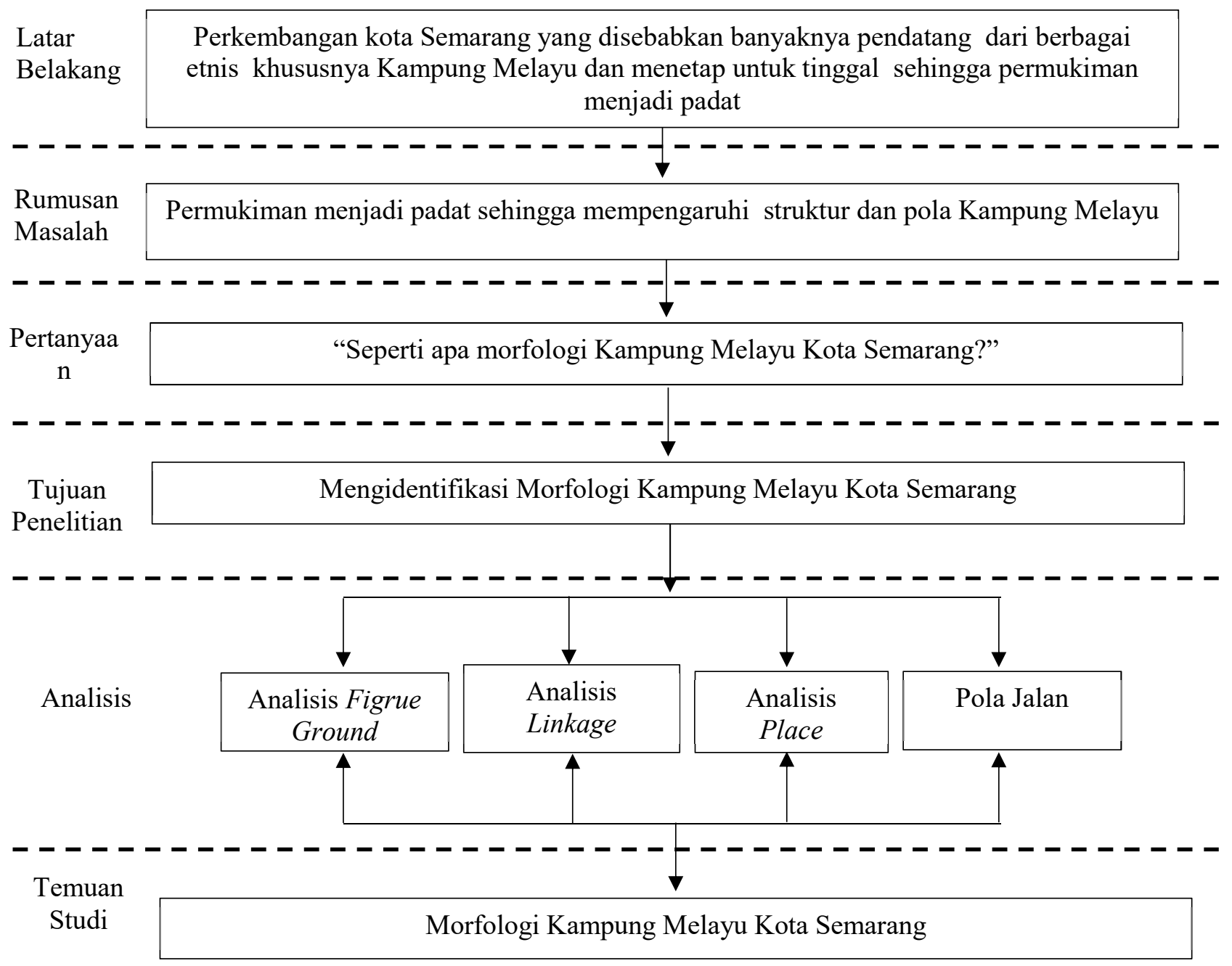




\section{HASIL DAN PEMBAHASAN}

Dalam pembahasan akan diuraikan hasil analisis dari apa yang telah di dapatkan dari hasil survey primer maupun sekunder yang berisi Histori Kawasan, Analisis Figure Ground, Linkage, Place dan Pola Jalan.

\subsubsection{Analisis Histori Kawasan}

Kampung Melayu adalah sebuah kampung kuno yang terbentuk pada sekitar akhir abad ke-16. Di awali dengan kepindahan tempat singgah kapal-kapal dan Mangkang ke Boom lama yang dimulai dari kapal-kapal kompeni pada tahun 1743, menyebabkan Boom lama yang merupakan cikal-bakal lahirnya kampung Melayu menjadi ramai oleh aktivitas perdagangan. Kampung Melayu Semarang merupakan hasil dari suatu proses morfologi yang panjang. Hal tesebut dapat dicermati berdasarkan gambar dibawah ini :

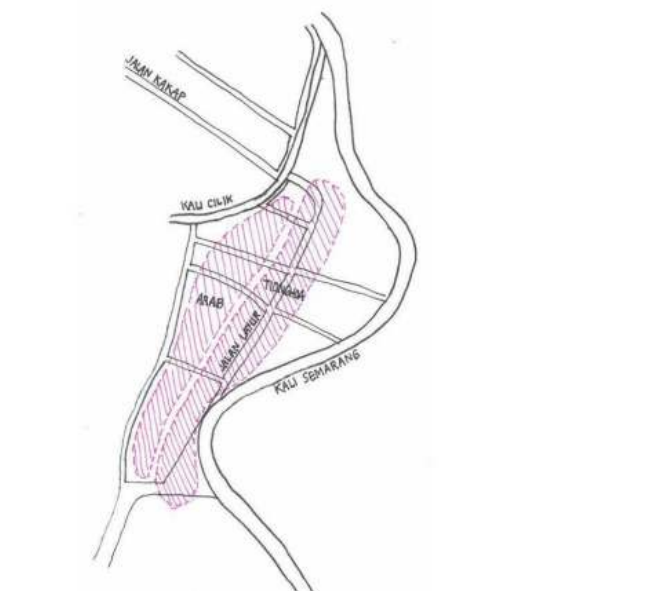

Kampung Melayu Awal Abad 17M

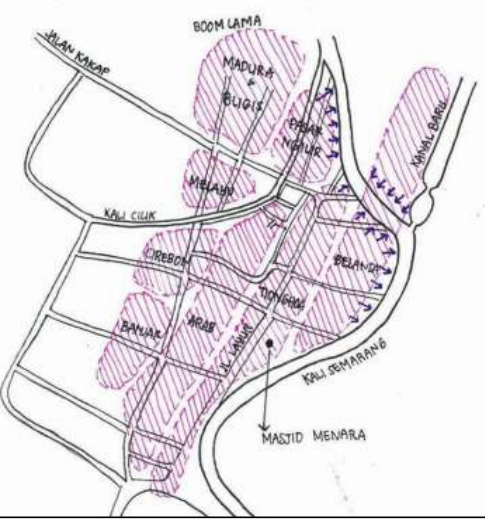

Kampung Melayu Awal Abad 19M

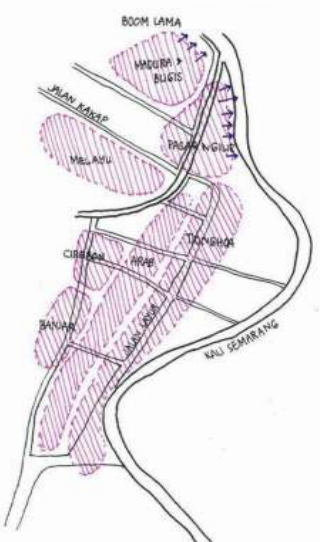

Kampung Melayu Akhir Abad 18M

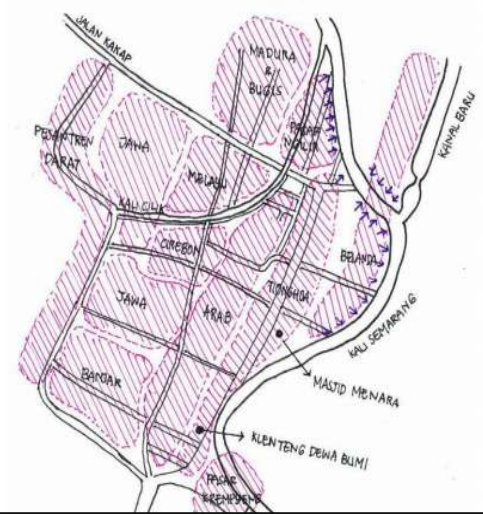

Kampung Melayu Akhir Abad 19M

Gambar 1. Sejarah Kampung Melayu

Sumber Sarinastiti, 2014 
Masyarakat Kampung Melayu merupakan masyarakat multi etnik, disamping terdiri dan masyarakat asli Semarang juga terdapat etnik lain yang berasal dan luar Semarang seperti etnik Arab, Tionghoa, Melayu, Banjar, Koja dan lain-lain. Keberagaman etnik masyarakat kampung Melayu juga berpengaruh terhadap toponimik nama lorong kampung yang ada di kampung Melayu Semarang, seperti kampung Banjar, kampung Cerbonan, kampung Pencikan, kampung Peranakan dan sebagainya. Terdapat kelompok kelompok kekerabatan pada masyarakat kampung Melayu Semarang, hal ini karena pada dasarnya masyarakat Kampung Melayu adalah multi etnik. Kekerabatan tersebut umumnya dimiliki oleh etnik tertentu. Terdapat kelompok kekerabatan dengan mengambil satu tokoh atau satu keluarga yang masih hidup sebagai pusat cikal bakal, selain itu juga berdasar wilayah yang mereka huni.

Pada tahun 1917 atau sebelum kemerdekaan daerah Kampung Melayu memang sudah dibentuk menjadi pemukiman. Namun di bagian barat, kawasan pemukiman tersebut masih belum terlalu kompleks. Sebagian besar masih berupa ruang terbuka hijau. Namun setelah kemerdekaan pemukiman penduduk semakin berkembang sehingga ruang terbuka hijau pun sangat sulit ditemui.

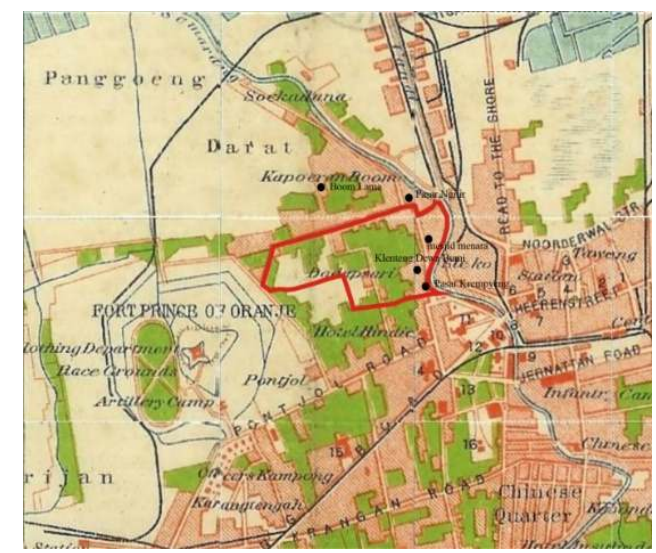

Gambar 2. Kampung Melayu Tahun 1917

Sumber : pamboedifiles.blogspot.com, 2012

\subsubsection{Analisis Morfologi Kota}

\section{A. Analisis Bentuk Figure Ground}

Analisis ini dapat dipahami melalui pola perkotaan dengan hubungan antara bentuk yang dibangun (building mass) dan ruang terbuka (open space). Pada analisis figure ground digambarkan dengan gambar peta black and white yang di dalamnya menjelaskan antara solid dan void suatu kawasan. Dengan penjelasan antara solid dan void pada figure ground di 
gambarkan pada peta warna hitam untuk solid dan warna putih untuk void. Warna hitam menunjukkan kawasan yang dibangun dan untuk semua ruang diluar massa itu ditunjukkan dengan warna putih.

Kampung Melayu memliki sifat heterogen, yaitu memiliki pola yang teratur dan tidak teratur. Kondisi ini diketahui pada pola permukiman yang berbeda antara figure ground yang berada pada sisi pinggiran jalan layur dengan yang ada di dalam kampung Melayu. Pola figure ground terlihat dari jalan raya lebih teratur dengan ukuran solid yang besar karena berupa toko, ruko maupun tempat ibadah. Jalan raya di kampung Melayu yang merupakan jalur penghubung dari arah Semarang Tengah menuju Semarang utara menjadikan jalan raya cukup ramai dan potensial untuk membuka usaha dan jasa. pola figure ground yang berada di dalam kampung bersifat tidak teratur. Hal ini terlihat dari pemukiman yang berada di dalam kampung tumbuh dan berkembang secara natural. Untuk elemen Void pada Kampung Melayu ditunjukkan dengan jalan, selain jalan pada wilayah studi juga terdapat lapangan yang berada ditengah permukiman.

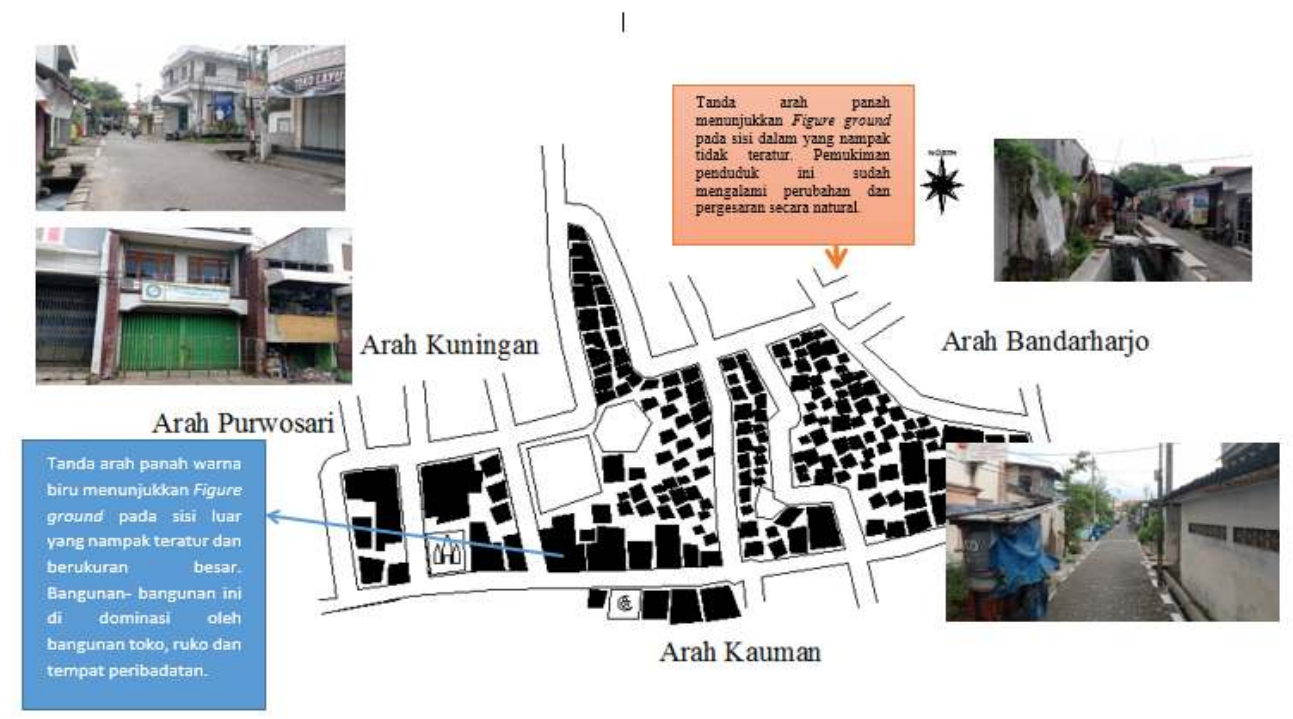

Gambar 3. Figure Ground Kampung Melayu Sumber : Hasil Analisis, 2020

\section{B. Sistem Linkage Kawasan}

Dalam linkage yang visual dua atau lebih banyak fragmen kota dihubungkan menjadi satu kesatuan secara visual. Sebuah linkage visual mampu menyatukan daerah kota dalam berbagai skala pada dasarnya menghubungkan dua daerah. 
Dalam analisis ini, menggambarkan bagaimana pola hubungan pergerakan yang ada di kawasan penelitian melalui analisis linkage kawasan. Menurut (Zahnd:1999), sistem linkage terdiri dari tiga pendekatan yaitu linkage visual, linkage struktural dan linkage kolektif. Linkage tidak lepas dari adanya jaring sirkulasi (network circulation). Network yang ada dapat berupa jalan, jalur pedestrian, ataupun bentuk-bentuk yang secara fisik menjadi penghubung antar bagia kota/kawasan. Pada kawasan penelitian, elemen linkage visual yang ada berupa garis (line), koridor (corridor), sumbu (axis). Elemen garis (line) pada kawasan penelitian ditunjukkan dengan jaringan jalan yang terdapat di permukiman. Elemen ini merupakan elemen yang sering digunakan untuk masyarakat dalam melakukan pergerakan untuk aktivitas sehari-hari. Elemen ini merupakan elemen yang paling mendominasi diantara elemen-elemen yang lain di kawasan penelitian.

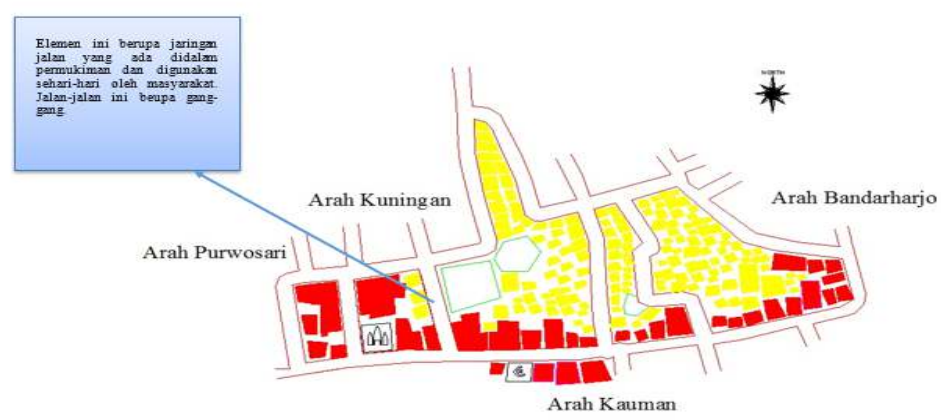

Gambar 4. Elemen Garis Kampung Melayu Sumber : Hasil Analisis, 2020

Sedangkan untuk elemen koridor (corridor) terbentuk oleh dua bangunan massa yang membentuk sebuah ruang yang menghubungkan dua daerah. Elemen ini digambarkan dengan jaringan jalan yang menghubungkan kawasan perdagangan yang ada yang ada di Jalan Layur. Pola pergerakan ini menjadikan koridor kawasan tersebut didominasi oleh pertokoan. 


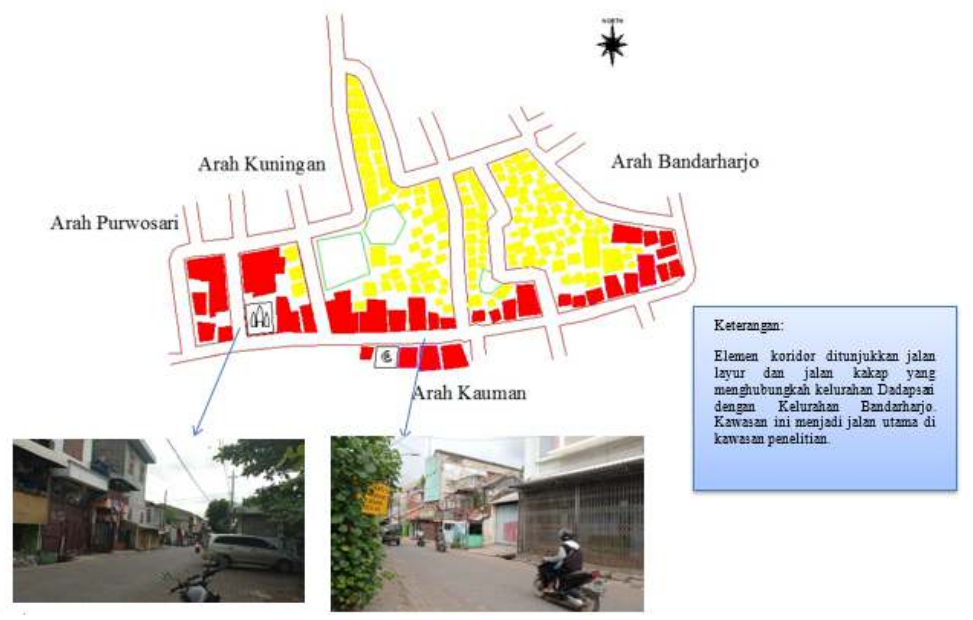

Gambar 5. Elemen Koridor pada Kampung Melayu Sumber : Hasil Analisis, 2020
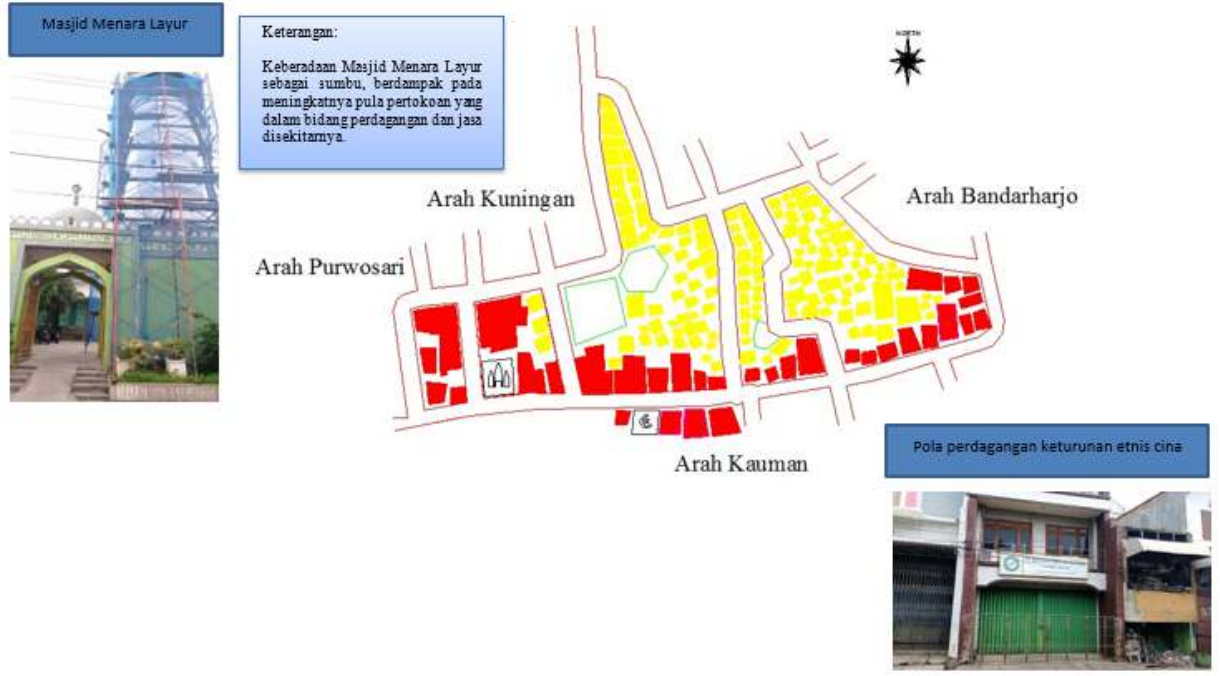

Gambar 6. Elemen Sumbu pada Kampung Melayu Sumber : Hasil Analisis, 2020

\section{Analisis Place}

Analisis place ini yaitu dengan mengamati adanya ruang atau space yang ada di kawasan penelitian sebagai place yang memiliki makna kehidupan bagi penduduk yang tinggal di dalamnya. Dengan proses sejarah, sebuah ruang akan menjadi place setelah memiliki makna. Kampung Melayu yang memiliki landmark masjid Menara Layur mengidentifikasikan orang- 
orang disekitarnya mengenal sebagai kampung religi dimana warganya yang tinggal merupakan orang- orang keturunan Arab. Selain orang melayu juga terdapat orang-orang Cina yang beragama Islam. Hal inilah yang menjadi cirri khas kampung Melayu dan dikenal masyarakat luar.

\subsubsection{Analisis Pola Jalan}

Melalui analisis pola jaringan jalan ini dapat diketahui bahwa pada pinggiran kampung melayu umumnya berkembang lebih teratur dibandingkan dengan yang ada di dalam kampung, hal ini dikarenakan bangunan-bangunan yang berisis pertokoan yang juga sebagai aktivitas perekonomian.

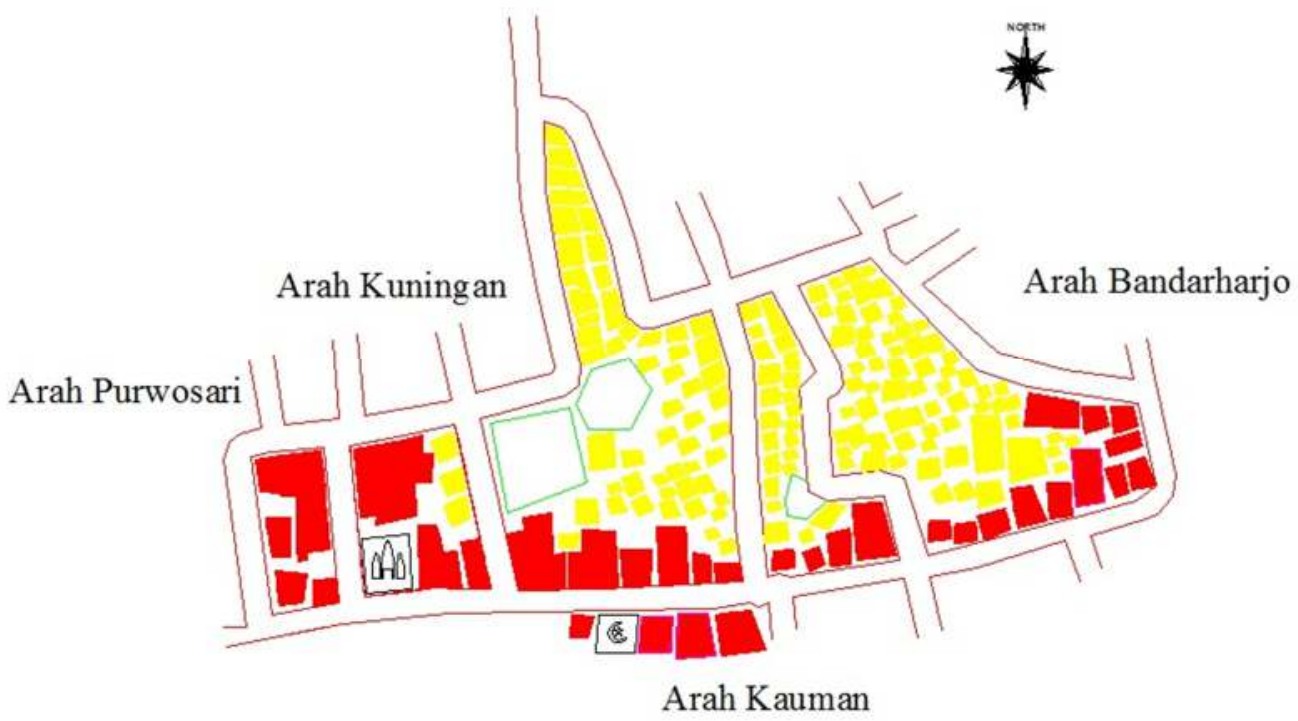

Gambar 7. Pola Jalan pada Kampung Melayu

Sumber : Hasil Analisis, 2020

\section{KESIMPULAN DAN SARAN}

\subsection{Kesimpulan}

Berdasarkan hasil analisis yang telah dilakukan, temuan dari penelitian yang berjudul identifikasi morfologi Kampung Melayu Semarang yaitu jika dilihat dari analisis figure ground, Kampung Melayu memiliki pola bangunan yang teratur dan tidak teratur. Jika dilihat dari analisis linkage pada Kampung Melayu memiliki elemen yang menghubungkan antar daerah, sedangkan analisis place pada Kampung Melayu memiliki karakteristik tersendiri sehingga 
apabila memasuki kawasan Kampung Melayu akan bisa ikut merasakan karakteristik yang ada di dalamnya.

\subsection{Saran}

Berdasarkan hasil analisis, maka saran yang diberikan yaitu :

a. Upaya pengembangan di Kampung Melayu Semarang dilakukan sesuai dengan karakter kawasan melalui pelibatan yang ada di dalamnya. Pada kawasan Kampung Melayu terutama pada koridor jalan utama merupakan pusat aktivitas perekonomian

b. Konsep pengembangan kawasan Kampung Melayu diupayakan tidak berdampak pada menurunnya kualitas lingkungan pada kawasan tersebut

c. Perlunya pedoman atau panduan dalam pengembangan Kampung Melayu yang sesuai dengan kebudayaan masyarakat serta lingkungan di sekitarnya agar dalam pengembangannya tidak terjadi kesalahan

\section{DAFTAR PUSTAKA}

Alie, C. P., \& Suwandono, D. (2013). Pengaruh Perkembangan Perkotaan Terhadap Morfologi Kampung Kauman Kota Semarang. Ruang, 1(1), 151-160.

https://ejournal3.undip.ac.id/index.php/ruang/article/view/2952

Bahar, F. S., \& Nursanty, E. (2012). KAJIAN URBAN VILLAGES PADA KAMPUNG ASLI KOTA Studi Kasus : Kampung Sekayu Semarang. 129-139.

https://pamboedifiles.blogspot.com/2012/08/peta-kuno-kota-semarang.html?m=1

Putri, M. A., Rahayu, M. J., \& Putri, R. A. (2016). Bentuk Morfologi Kawasan Permukiman Urban Fringe Selatan Kota Surakarta. Jurnal Pengembangan Kota, 4(2), 120. https://doi.org/10.14710/jpk.4.2.120-128

Sarinastiti, A. (2014). Konsep waterfront pada permukiman etnis Kali Semarang (Doctoral dissertation, Undip).

Sitompul, C. M., \& Roychansyah, M. S. (2018). Identifikasi Perkembangan Morfologi Kotalama Semarang. D007-D013. https://doi.org/10.32315/ti.7.d007

Susanti, A. D., \& Ikaputra, I. (2020). Morfologi Urban Artefak Kampung Kota. MARKA (Media Arsitektur Dan Kota) : Jurnal Ilmiah Penelitian, 4(1), 17-26. https://doi.org/10.33510/marka.2020.4.1.17-26 